\title{
O beat e o bit do rock brasileiro: internet, indústria fonográfica e a formação de um circuito médio para o rock no Brasil
}

\author{
Danilo Fraga ${ }^{1}$ \\ UFBA \\ danfraga@gmail.com
}

\begin{abstract}
Resumo: Uma das principais características do rock brasileiro é que ele sempre circulou pelo mainstream fonográfico. Em cinqüenta anos de história, o rock brasileiro foi lançado por grandes gravadoras, esteve em trilhas sonoras de telenovelas, entre outros elementos típicos desse modelo de distribuição. Mas, nas últimas duas décadas, é possível notar a formação de um circuito de rock brasileiro entre o mainstream e o underground, um circuito médio. Os principais fatores que possibilitaram a formação desse circuito foram a ressaca do rock brasileiro dos anos 80 , o surgimento de novas tecnologias de gravação e, principalmente, a possibilidade de distribuição a partir da internet. O objetivo desse artigo é investigar se essa mudança no modo que o rock brasileiro circula pela indústria fonográfica provoca mudanças mais profundas no gênero.
\end{abstract}

Palavras-chave: Rock brasileiro, gêneros midiáticos, internet.

Abstract: One of the most important Brazilian rock characteristics is It's circulation on the phonographic mainstream. The Brazilian rock, in fifty years of history, was always sold by majors, was in Brazilian soup-operas soundtracks, and so on. But, in the last decades, it's possible to note the formation of a middle circuit, between the mainstream and underground. The most important factors of that phenomenon are the takeover of the Brazilian eighty's rock and roll, the rise of the digital technologies of record and the internet. This article will investigate how this change in the circulation of Brazilian rock reflects on other characteristics of the genre.

Keywords: Brazilian rock, musical genre, internet

\footnotetext{
1 Danilo Fraga (danfraga@gmail.com) é mestre pelo Programa de Pós-Graduação em Comunicação e Cultura Contemporâneas/UFBA, faz parte do Grupo de Mídia e Música Massiva, coordenado pelo Prof. Dr. Jeder Janotti Júnior, e, além disso, é crítico musical e repórter do Jornal A Tarde, da Bahia.
} 
Résumé: Une des caractéristiques principales du rock bresileire est qu'elle l'a toujours circulé pour le mainstream fonográfico. En cinquante ans d'histoire, lê rock bresileire a été lancée par de grands enregistreurs, était dans les voies sonores des pregraime de television, entre d'autres les éléments typiques de ce modèle de distribution. Mais, dans le bout les deux décennies, il est possible de noter la formation d'un circuit de rock bresileire entre le mainstream et le underground, un circuit moyen. Les facteurs principaux qui rendent la formation possible de ce circuit avaient été l'undertow du rock bresileire des années 80 , la germination de nouvelles technologies de l'écriture et, principalement, la possibilité de distribution de l'Internet. L'objectif de cet article est d'étudier si ce changement de la manière dont lê rock bresileire circule pour l'industrie de fonográfica provoque des changements plus profonds du genre.

Mots-clé: Rock bresileire, genre, internet

Resumen: Una de las principales características del rock brasileño es que siempre ha circulado por el mainstream fonográfico. En cincuenta años de historia, el rock brasileño fué lanzado por grandes empresas, estuvo en bandas sonoras de telenovelas, dentre otros elementos típicos de este modelo de distribución. Pero en las ultimas dos décadas, es posible notar la formación de un circuito de rock brasileño entre el mainstream y el underground, un circuito medio. Los principales factores que posibilitaron la formación de este circuito fueron la resaca del rock brasileño de los años 80, la aparición de nuevas tecnologias de grabación y, principalmente, la posibilidad de distribución desde internet. El objeto de este artículo es investigar si este cambio en la manera como el rock brasileño circula en la industria fonográfica ha producido otros cambios más extensos en el género.

Palabras clave: rock brasileño, géneros midiáticos, internet.

\section{Introdução}

Nem todo rock feito no Brasil é chamado rock brasileiro. Pode parecer estranha a constatação, mas para atestar sua veracidade não é preciso ir muito além de uma rápida análise das prateleiras de uma loja de discos. É que os grupos brasileiros de rock também lançam álbuns de heavy metal (Soldiers of sunrise, do Viper), hard rock (Metal mania, Robertinho do Recife), punk rock (Tente mudar o amanhã, Cólera), indie rock (Stratopumas, Stratopumas) ou rock progressivo (Zebra, Vímana) - entre tantas outras denominações que o rock recebeu nas últimas décadas. E, lojas de discos especializadas, esses discos estão separados do rock brasileiro, que em uma prateleira à parte dos outros subgêneros do rock and roll, em uma prateleira estranha, que abriga, lado a lado, álbuns muito diferentes entre si. 
Alguns desses álbuns não são muito diferentes dos discos de heavy metal (Gates of metal fried chicken of death, Massacration), de hard rock (Entradas e bandeiras, Rita Lee \& Tutti-Frutti), punk rock (O concreto já rachou, Plebe Rude). Outros mais parecem samba (O Bloco do eu sozinho, dos Los Hermanos), samba-rock (Samba esquema noise, Mundo Livre S/A), maracatu (Afrociberdelia, Chico Science \& Nação Zumbi, 1993) ou bossa-nova (Novos Baianos F.C., Novos Baianos). E, mesmo assim, na loja de discos, estão todos na prateleira de rock brasileiro.

O processo de rotulação da música popular massiva é complexo e envolve questão que vão além da simples classificação a partir de aspectos musicais comuns. Assim, ao que parece, o rock brasileiro não é apenas o rock feito por brasileiros, não é o rock cantado em português e nem é o rock com elementos da música popular brasileira. Ele também não é a simples soma dessas três características. Os últimos trabalhos do grupo de Mídia e Música Popular Massiva da Universidade Federal da Bahia, coordenado por Jeder Janotti Júnior, mostram que o processo de rotulação na música popular massiva diz respeito a aspectos expressivos dos produtos, de sua relação com os suportes midiáticos, de suas condições de produção e reconhecimento e do modo como ele pressupõe suas estratégias de leitura. E não seria diferente com o processo de rotulação do rock brasileiro. Mas, entre as características musicais e performáticas igualmente importantes, esse artigo pretende se concentrar no papel que a relação do rock brasileiro com a indústria fonográfica em sua rotulação.

Em cinqüenta anos de história, o rock brasileiro foi lançado por grandes gravadoras, esteve em trilhas sonoras de telenovelas, entre outros elementos típicos desse modelo de distribuição. Ao circular pelo mainstream fonográfico, o rock brasileiro acaba assumindo algumas características básicas desse circuito. Entre estratégia de distribuição os meios de comunicação são utilizados de maneira intensiva, com remessas de grande volume para lojas de departamento do mundo todo, divulgação na televisão (através de videoclipes, participação em programas de auditório, etc.), rádio (nos horários nobres da programação), cinema (trilha sonoras, filmes-biografias), internet (em portais de música e cultura), telefonia celular (toques de celulares, papéis de parede) e em outros meios de comunicação de massa. E, a circulação pelo mainstream, tem reflexos na própria música e na performance, que deve estar de acordo com o horizonte de expectativas do público, projetado nos 
gêneros musicais. É essa umas das principais características do rock brasileiro, que o diferencia dos grupos que circulam no underground, que partilham de outras rotulações.

Mas o que esse artigo pretende mostrar é que, no começo dos anos 90, começou a ser esboçado um circuito médio para o rock brasileiro, entre o mainstream e o underground. E quais as principais conseqüências desse circuito para o gênero musical rock brasileiro.

\section{Farto do Rock'n Roll}

"O pop/rock brasileiro atravessa uma séria estagnação", concluía o editorial de julho de 1990 da revista Bizz (Editora Abril). Naquele mês, Cazuza (Burguesia, 1989) havia acabado de morrer. E, por essa e outras, o começo dos anos 90 não foi um dos melhores momentos da história do rock brasileiro. Entre os principais grupos que dominaram os meios de comunicação de massa nos anos 80, apenas Legião Urbana (As quatro estações, 1989), Paralamas do Sucesso (Big bang, 1989) e Titãs (Õ blésq blom, 1989) ainda faziam sucesso na virada da década. Além disso, os novos grupos de rock brasileiro, que apareceram no final da década, não pareciam propor qualquer novidade para o mercado fonográfico, ao utilizar as mesmas estratégias do rock brasileiro dos anos 80. O grupo Uns \& Outros, por exemplo, alcançou o sucesso com a canção Carta aos missionários, de seu segundo disco (Uns \& outros, 1989), mas "se perderam de tão empenhados que estavam em perseguir Renato Russo e companhia. Eles pareciam o Legião Urbana, mas não eram o Legião Urbana" (Dapieve, 2004:185). Esses grupos insistiam nas mesmas estratégias midiáticas do começo da década de 80, mas o panorama musical não era mais o mesmo.

Por essas e outras, a relação do rock brasileiro com o mainstream da indústria fonográfica estava desgastada, no começo dos anos 90. Nessa mesma época, o Brasil passava por uma crise mais ampla em 1989, a inflação acumulada no final do governo de Sarney chegava a $1764,86 \%$ e, no ano seguinte, o faturamento da indústria fonográfica brasileira caiu 40\%. Assim, para os grupos de rock brasileiro dos anos 80 que se dirigiam a um público amplo, ficava cada vez mais difícil recuperar a grande vendagem de alguns anos atrás, que, aliás, eram muito altas. Os Paralamas do Sucesso, por exemplo, que alcançaram 750 mil cópias vendidas com 
Selvagem? (1986), vendiam cada vez menos: entre Bora bora (250 mil cópias, 1988), Big bang (200 mil, 1989), Os grãos (100 mil, 1991) e Severino (55 mil, 1994) a diferença é notável.

Mas, na contramão dessa tendência, o grupo mineiro de heavy metal Sepultura alcançou o sucesso internacional no final da década de 80 a partir de uma estratégia de circulação típica do circuito alternativo e muito diference do rock brasileiro dos anos 80. O primeiro disco do grupo, lançado no auge do sucesso dos grupos dos anos 8o, é um álbum split² (Bestial devastation, 1985), lançado pelo selo independente Cogumelo Records. O próximo lançamento do Sepultura (Morbid visions, 1986), também independente, vendeu dez mil cópias em todo Brasil. Em 1988, o grupo assinou um contrato com uma gravadora internacional especializada em rock pesado, a Roadrunner, e se tornou o primeiro grupo brasileiro a ter sucesso no mercado internacional. O próximo álbum do Sepultura (Beneath the remains, 1989) vendeu 600 mil cópias e foi divulgado com uma turnê nos Estados Unidos e Europa, mas era apenas o começo. Mas o sucesso do grupo se consolidou mesmo com o lançamento de Arise (1991), que vendeu mais de 800 mil cópias e teve uma turnê com apresentações em mais de 39 países, incluindo Indonésia, Japão e Austrália. Nos anos 90, o grupo deixou de circular apenas pelo circuito do heavy metal para dialogar com o mainstream fonográfico internacional, com Chaos A.D. (1993) e Roots (1996). Em seus primeiros discos, o Sepultura tinha muito pouco a ver com o mainstream da indústria fonográfica brasileira, ou mesmo com o rock brasileiro e a música popular brasileira de um modo geral. O grupo estava diretamente ligado ao circuito do heavy metal e circulava em espaços especializados no subgênero. Além de circular por espaços segmentados, o grupo adotava estratégias típicas do circuito alternativo, como a dissolução do canto inteligível no estilo gutural3, a utilização do inglês como língua das composições e, pelo menos no início da carreira, nenhum diálogo com a música popular brasileira.

2 Um álbum split (ou somente split) é um álbum musical que contêm faixas de dois ou mais artistas. Os splits foram inventados a partir da divisão dos vinis entre lado A e lado B, com um lado contendo as músicas de um artista e o outro lado contendo músicas do outro. Este formato foi muito utilizado a partir do início da década de 80 por bandas de punk rock, hardcore, indie rock e heavy metal.

$3 \mathrm{O}$ vocal gutural é uma técnica vocal comum no metal pesado, em que a emissão sonora se dá a partir do ar que vem direto do estômago e produz um som rouco, grave ou profundo, podendo se referir tanto ao vocal grave quanto gritos. 


\section{Outsiders}

O sucesso mundial do Sepultura a partir de uma estratégia de consumo segmentado e a diminuição do espaço para novos grupos de rock brasileiro no mainstream indústria fonográfica local, abriu espaço para que, no final da década de 80 e começo dos anos 90, alguns grupos brasileiro de rock passassem a utilizar estratégias típicas de circuitos de consumo alternativo - e, portanto, distantes das estratégias utilizadas pelo rock brasileiro nas últimas décadas. Entre essas estratégias estão a utilização do inglês como língua principal para as letras, a adoção de uma dicção típica dos grupos internacionais de rock and roll e distante da música popular brasileira, a utilização de equalizações que colocam a voz em segundo plano, o desinteresse por qualquer tentativa de diálogo com a música popular brasileira, a adoção de suportes de armazenamento não-oficiais e a circulação em locais e meios especializados. Esses grupos eram distribuídos, principalmente, a partir de fitas cassetes com gravações caseiras ou, eventualmente, por lançamentos em disco por selos especializados. Entre esses grupos de rock independente estavam o Pin Ups (Time will burn, 1990), Second Come (You, 1991), Beach Lizards (Lagarto de praia, 1991), Killing Chainsaw (Killing chainsaw, 1992), Úteros em Fúria (Úteros em fúria, 1992), Anarchy Solid Sound (Anarchy solid sound, 1993), Mickey Junkies (Stoned, 1995), brincando de deus (Better when you love (me), 1995) e Dash (Uh-la-la, 1995).

Mas, apesar desse afastamento em relação às principais características, os grupos de rock alternativo do começo dos anos 90 são importantes para o rock brasileiro dos anos seguintes. Não é uma influência direta no estilo das canções, mas uma influência a partir, principalmente, do circuito independente esboçado por esses grupos e que só seria completamente desenvolvido na primeira década do século oo. A partir desses experimentos, aos poucos, foi se formando um circuito independente de rock no Brasil com um discurso ativo de preservação da livre expressão de grupos marginais à cultura de massa e pontos de venda e de exposição funcionando numa loja alternativa ao grande mercado fonográfico (Thorton, 1996). "Os outsiders, que fizeram rock em inglês, podem não ter contribuído esteticamente para o futuro do rock brasileiro, mas o ideal que criaram, para a formação de um mercado independente, talvez seja um dos recados mais importantes já dados em toda a década de 80" (Jumpei, 2004: 77). 


\section{O mundo gira}

O afastamento progressivo do rock brasileiro do mainstream encontrou, em meados dos anos 90, um ambiente fonográfico que, cada vez mais, abria espaço para novas possibilidades na produção, circulação e consumo da música popular massiva. O fortalecimento do circuito alternativo e a constante relação dos grupos de rock brasileiro com esse circuito criaram uma situação interessante para o gênero na indústria fonográfica brasileira que pode ser interpretada, em boa medida, como a preparação para as transformações causadas pela adoção das tecnologias digitais e da distribuição pela internet. Os primeiros sinais dessas modificações podem ser notados, principalmente, na adoção da tecnologia digital do compact disc como padrão de armazenamento sonoro, na inauguração da filial brasileira da MTV e numa relação mais complexa entre os selos alternativos e as grandes gravadoras. Esse processo seria aprofundado anos mais tarde, na década de oo, a partir da disseminação da tecnologia digital e da possibilidade de autopublicação musical trazida pelo desenvolvimento da rede mundial de computadores. Para Dias, "dentro de um planejamento de reestruturação empresarial, a indústria fonográfica iniciou, nos anos 90, um processo que resultaria na terceirização da produção e na adoção da tecnologia digital" (2000).

Em meados da década de 90 o compact disc, o primeiro suporte digital de reprodução que substituiria em escala mundial o vinil, foi popularizado no Brasil. Nos anos 90, o suporte ganhou a adesão das demais gravadoras e começou a ser difundido no Brasil, na mesma época em que foram comercializados os primeiros aparelhos reprodutores do novo suporte. Na época de seu lançamento, o CD podia comportar 74 minutos de gravação4, contra os 40 minutos de um LP, o que praticamente dobra a possibilidade de duração dos álbuns de rock brasileiro. Em meados dos anos 90 as gravadoras brasileiras reduziram expressivamente a fabricação dos discos de vinil. Em 1991 a venda total de LPs em vinil, no Brasil, era de 28,4 milhões de unidades, contra 7,7 milhões de unidades de CD. Em 1994, ano em que foi lançado Da lama ao caos, a situação se inverteu e foram vendidos 14,4 milhões de LPs e 40,1 milhões de CDs. No ano seguinte a tendência se manteve e venda de LPs caiu pela a metade, 7,7 milhões, contra 56,7 milhões de CDs (Dias,

4 Hoje, alguns compact disc comportam até 80 minutos de som 
2000: 106). Mas a mudança de suporte para a música popular massiva trouxe outras mudanças para a indústria fonográfica brasileira. A princípio, “o uso preponderante do compact disc foi o principal fator para a exploração e a viabilização dos catálogos das grandes gravadoras" (Shuker, 1999: 48). Nesse momento, as pessoas passaram a substituir suas antigas coleções de discos de vinil pelos discos digitais, em um momento de grandes lucros para o sertor. Além disso, ao relançar o catálogo de vinis em $\mathrm{CD}$, a indústria fonográfica proporcionou um aumento considerável de informação musical disponível no mercado, o que possibilitou a mistura de gêneros musicais da década de 90, a conseqüente crise no setor e o desenvolvimento do circuito alternativo.

Mas, ao transformar o som em um arquivo digital, o CD significou o primeiro passo para a facilitação de gravação e distribuição da música popular massiva. "Um primeiro ponto diz respeito à desmaterialização da música a partir de sua digitalização. Dessa forma, a noção de produtos fechados tais como o disco e junto com ele o aparelho para reprodução sonora estão sendo problematizados, explicando parte dos problemas da indústria fonográfica” (Sá, 2006: 15). A tecnologia digital também facilitava a manipulação e arquivamento da música. E no final dos anos 90, quando a indústria passa a oferecer no mercado o CD gravável, foram dados os primeiros passos para a substituição em larga escala do vinil e da fita cassete pelo CD. E, como a prensagem do CD era muito mais barata do que a dos LPs e o tamanho diminuto dos álbuns reduzia em muito os custos com a parte gráfica do produto, o CD passou a ser o suporte ideal para os circuitos alternativos de rock no Brasil. Essa tecnologia também se encaixava perfeitamente às necessidades do circuito de rock brasileiro que estava se formando, ainda relacionado ao mainstream, mas com muitos elementos da cena alternativa. Para Michael Herschmann e Maurício Kischinhevsky, "a chegada da tecnologia de gravação de CDs ao grande público funcionou como um tiro no pé" (2005: 6).

O começo das transmissões da MTV Brasil também foi importante para a consolidação do circuito do rock brasileiro. A emissora de televisão existe nos Estados Unidos desde 1981, mas só chegou ao Brasil em 1990. E, desde então, a MTV 
Brasil se apresenta como um meio de comunicação segmentado 5 que tem como objetivo atingir o público jovem. E uma das formas encontradas para alcançar tal objetivo foi divulgar a produção de rock and roll internacional e de rock brasileiro. "Além do papel que desempenhou para o fortalecimento da indústria fonográfica, ao amplificar o consumo musical, a MTV também consolidou o formato televisivo direcionado para um público específico: a juventude” (Gutmann, 2005: 71). A emissora de televisão assumia sua segmentação a partir de programas especializados em diversos estilos de rock, como o rock alternativo (Lado b), heavy metal (Fúria), rap (Yo!) e o hardcore (Gás total) ${ }^{6}$. É interessante notar que a alternativa segmentada de televisão aparece exatamente quando o circuito mainstream tem pouco espaço para o rock brasileiro. Essa alternativa aos meios de comunicação de direcionamento amplo dava ao rock brasileiro dos anos 90 a possibilidade de consolidar uma cadeia midiática específica para o rock brasileiro, ainda próxima ao mainstream, mas de caráter segmentado. Assim, "a MTV possibilitava ao rock brasileiro uma existência independente do grande mercado fonográfico e possibilitou que as gravadoras começassem a apostar em lançamentos segmentados” (Janotti Jr. 2003: 100) - o que, pouco a pouco, fez os grupos em inglês serem cada vez mais raros.

\section{Independência ou morte}

Esses dois fatores foram de extrema importância para o fortalecimento do circuito de rock brasileiro que começou a se formar nos anos 90, antes mesmo da popularização da internet. É claro que o circuito alternativo de rock and roll sempre existiu no Brasil, desde, ao menos, os anos 6o. Mas o desenvolvimento dessa cena sempre foi atrapalhado pelo alto custo na fabricação dos discos de vinil, pela centralização dos meios de comunicação de massa e, principalmente, pela dificuldade de distribuição dos discos. Por isso, entre outros motivos, o rock brasileiro é um fenômeno que se desenvolveu, quase que totalmente, no mainstream. A formação de um circuito de rock brasileiro mais próximo do underground - o que inclui novos espaços de produção, circulação e consumo - só foi esboçada no começo dos anos 90. Um dos pioneiros nessa área é o selo Baratos afins que, ainda nos anos 80, lançou

5 A MTV Brasil é a primeira televisão segmentada do país e, no ano de seu lançamento, o sinal da emissora era recebido em menos de seis milhões de lares, em apenas 51 cidades brasileiras. 6 Para Shuker, "até o advento da MTV, no final da década de 1980, o rádio era indiscutivelmente o mais importante veículo de difusão da música pop” (1999: 225). 
discos de Arnaldo Baptista (Singing alone, 1982), Ratos de Porão (Crucificados pelo sistema, 1983) e Voluntários da Pátria (Voluntários da pátria, 1984), entre outros. Nessa mesma época, existiam outros selos menos influentes, como o mineiro Cogumelo (Morbid visions, Sepultura) e o curitibano Vinil Urbano (Cemitério de elefantes, vários).

Mas esses empreendimentos tinham como principal problema a distribuição dos discos, uma parte da cadeia midiática que, tradicionalmente, necessita de um aparato logístico típico de uma grande gravadora. Nessa época, algumas formas alternativas de comercialização foram adotadas pelos selos independentes, como a venda de discos em shows, a entrega pelos correios e a união entre pequenos selos para a distribuição conjunta - práticas que, de uma maneira ou de outra, continuam até hoje. Mas, ainda nos anos 8o, alguns selos de rock brasileiro, como o Plug!, Rock It! e Tinitus, conseguiram resolver o problema da distribuição ao se associar à grandes gravadoras e se valer de seu aparato logístico.

Esse foi o modelo que, ao ser adotado por muitos selos dos anos 90, possibilitou o crescimento do circuito alternativo e o desenvolvimento de uma mentalidade profissional que seria utilizada no século 21, com o advento da rede. Assim, "os contratos de distribuição (entre os selos e as grandes gravadoras) eram e continuam sendo os mais freqüentes, devido às dificuldades que essa área apresenta para as empresas menores" (Vicente, 2005: 9). Os selos procuravam nas grandes gravadoras uma forma de distribuir seus produtos, enquanto as gravadoras procuravam nos selos o diálogo com um público que, até então, não conseguiam atingir de maneira eficiente e uma forma de não se arriscar em lançamentos incertos. Para Keith Negus, "lentas em compreender onde se dão as novas tendências, entorpecidas e incapazes de se mover com rapidez suficiente para atrair novos talentos, as grandes gravadoras esperam e logo correm atrás dos repertórios de pequenas companhias independentes que já tenham provado o potencial de seus novos talentos”. (2005: 68). Desde o final da década de 80, quando o espaço na indústria fonográfica para o rock brasileiro encolheu, o investimento em elencos milionários declinou, acompanhando o recuo nas vendagens, e o garimpo de novos talentos foi terceirizado, ficando por conta de selos com os quais eram fechados contratos de distribuição. Na década de 90, quando o mercado reagiu, as grandes 
gravadoras mantiveram o modelo, com estruturas próprias relativamente enxutas e parcerias com os selos. Assim, "ao longo dos anos 90 foi se constituindo uma nova ecologia do mercado, com as gravadoras independentes passando a preencher um espaço não mais ocupado pelas majors, cuidando tanto da formação de novos artistas quanto da prospecção e atendimento a segmentos musicais emergentes ou de mercado muito restrito" (Vicente, 2005: 9).

Nessa época, o Plug!, distribuído pela BMG, lançou discos do Pato Fu (Rotomusic de liquidificapum, 1993). O Tinitus estava ligado à Polygram e lançou Virna Lisi (Esperar o que?, 1993), Banda Bel (Rei do Rio, 1992) e Yo-Ho-Delic (Yoho-delic, 1992). E o Rock It!, distribuiu pela EMI, grupos como Gangrena Gasosa (Welcome to terreiro, 1993), PELVs (Peter Greenaway's surf, 1993), Peter Perfeito (Funk rock nervoso, 1995). Além disso, as gravadoras criaram selos especializados dentro de sua própria estrutura administrativa. O selo Chaos foi o selo criado pela Sony Music para lançar grupos como Skank (Skank, 1993), Gabriel, o Pensador (Gabriel, o pensador, 1993), Jota Quest (Jota Quest, 1996), Mestre Ambrósio (Mestre Ambrósio, 1996) e Jorge Cabeleira e o Dia em que Seremos Inúteis (Jorge Cabeleira e o dia em que todos seremos inúteis, 1998). A Warner Music lançou o selo Banguela, hoje chamado de Excelente Discos, para lançar os discos dos Raimundos (Raimundos, 1994), Little Quail \& the Mad Birds (Lírou quêiol en de méd bârds, 1994), Maskavo Roots (Maskavo roots, 1995) e Graforréia Xilarmônica (Coisa de louco II, 1995). No final dos anos 90, o circuito alternativo de rock brasileiro estava tão desenvolvido que possibilitou o surgimento de outras estratégias de distribuição, como é o caso da distribuição de CDs em bancas de revistas, implantada pelo selo Universo Paralelo, que encarta seus produtos na revista Outra Coisa, especializada em música. Em 1999, o cantor Lobão lançou seu disco $A$ vida é doce através desse selo. Nas bancas e custando somente $\mathrm{R} \$ 9,90$ (o preço médio do CD na época era de $\mathrm{R} \$ 20,00)$, o álbum atingiu facilmente a marca das 100 mil cópias vendidas.

\section{Computadores fazem arte}

Mas apesar de todo esse movimento foi apenas no começo do século 21, com a possibilidade da autopublicação trazida pela rede mundial de computadores, que o circuito alternativo do rock brasileiro alcançou sua maturidade. Até o final da década 
de 90, apenas cinco grandes gravadoras detinham $85,28 \%$ do mercado mundial, com a participação Universal (23,1\%, incluída a Polygram), Warner (20,68\%), Sony Music (15,14\%), EMI (14,4\%) e Bertelsmann (no Brasil, BMG - 11,96\%) (Herschmann e Kischinhevsky, 2005). Mas os lucros que essas companhias conseguiram a partir da venda de discos só diminuíram nos últimos anos. Entre os anos de 1983 e 1995, o faturamento mundial das gravadoras multinacionais passou de dez para 40 bilhões de dólares, segundo dados da IFPI7. Mas, a partir de 1999, essas gravadoras registraram uma rápida queda nas vendas de discos, de forma que, no ano de 2006, a queda havia chegado a 25\%. E esse processo é ainda mais agudo em relação à indústria fonográfica brasileira que, segundo dados da $\mathrm{ABPD}^{8}$, no mesmo período sofreu uma queda de $31 \%$ em seu faturamento. A quantidade de artistas campeões de vendagem só fez diminuir. E, com números tão reduzidos, a indústria se viu forçada a mudar os parâmetros de suas tradicionais premiações aos mais vendidos: o disco de ouro, que até 2003 era concedido a quem tivesse mais de 100 mil cópias vendidas de seu álbum, tornou-se troféu para quem vendesse 50 mil unidades. E as demais categorias também se apequenaram.

Mas essa conclusão parece descabida se colocada à frente a outra afirmação, também verdadeiras, de que "nunca se consumiu tanta música como hoje” (Sá, 2006: 2). O desenvolvimento tecnológico sempre esteve em estrita relação com a música popular massiva, em seus processos de produção, distribuição e consumo. As grandes gravadoras, pelo menos até a década de 1980, trabalharam de maneira verticalizada, centralizada e dominaram as principais etapas do negócio de discos, da produção à distribuição. Mas, da década de 90 para cá, a produção, distribuição e consumo da música sofreram uma grande modificação a partir das novidades tecnológicas, principalmente as tecnologias digitais de gravação e reprodução e as possibilidades de distribuição trazidas pela rede. A IFPI estima em 20 bilhões o número de downloads ilegais de música realizados no mundo em 2005, sendo um bilhão deles atribuído ao Brasil. Assim, a crise que assola a indústria fonográfica hoje é bem distinta daquela experimentada no fim dos anos 80. O vivemos é um processo de

7 International Federation of the Phonographic Industry, ou, em português, Federação Internacional da Indústria Fonográfica. O site da IFPI (ifpi.org) apresenta uma série de dados estatísticos, estimativas de desempenho econômico, além das empresas associadas.

8 A Associação Brasileira de Produtores de Disco, ABPD, também mantêm em seu site (abpd.com.br) dados sobre o mercado fonográfico brasileiro. 
reestruturação da indústria fonográfica que envolve a queda nas vendas de música em suportes físicos, como o disco de vinil e o compact disc, e o aumento da troca de informações na rede (Herschmann e Kinchinhevsky, 2005).

O armazenamento de músicas em arquivos digitais já existia desde a década de 80, mas foi somente a partir da criação do formato MPEG-1 Layer 3, o MP3, que se tornou possível a gravação de músicas em arquivos menores e mais facilmente manipulados. O MP3 é um padrão internacional de digitalização de áudio que permite a compressão de sons em até $1 / 12$ do tamanho de outros formatos, como o WAV, guardando suas principais características em uma qualidade próxima a um compact disc. Mais ou menos na época da popularização da MP3, a internet se tornou popular no Brasil, com o surgimento dos primeiros provedores de acesso comercial o que possibilitou a troca desses arquivos pela rede. De olho no novo mercado, muitas gravadoras e selos se estabeleceram na internet reproduzindo na rede a lógica do mercado de discos, ao lançar seus próprios serviços de venda de arquivos de $\mathrm{MP}_{3}$ pela rede. Mas, essa situação se modificou pouco tempo depois, a partir dos programas de $\mathrm{P} 2 \mathrm{P}$, como o Napster, que permitem a troca de músicas sem passar diretamente pelas grandes gravadoras. O Napster saiu do ar em 2001, devido a uma ação judicial movida pelas gravadoras, que acusavam os criadores do software de estimulo à pirataria. Mas logo apareceram outros programas, como o Kazaa, Grokster, E-Mule e Soulseek, que realizam o mesmo tipo de troca de arquivos musicais. "A troca de música na rede através de ferramentas par-a-par como o Napster e mais recentemente do Kazaa e outras; as rádios online, a criação do iPod aparelho com alta capacidade de estocagem de músicas em formatos variados e a venda de música através de lojas virtuais como a I-Tunes - constituem em conjunto um cenário marcado por novas tecnologias que colocam em questão a gramática de todos os meios de comunicação ligados à reprodução e consumo musical" (Sá, 2004: 17).

Mas é preciso tomar cuidado ao decretar o fim da indústria fonográfica, do mainstream musical ou de seus formatos padrões, como a canção e o álbum. O que há, de fato, é uma reconfiguração de todas essas instâncias, até porque o circuito alternativo também é parte integrante da indústria fonográfica. E, antes de anunciar 
o fim do mainstream musical, é preciso notar como suas estratégias migram para outros suportes tecnológicos.

\section{7. $O$ circuito médio}

O rock brasileiro sempre circulou pelo fluxo principal dos meios de comunicação de massa e, em conseqüência disso, os discos dos principais grupos desse gênero sempre assumiram algumas características típicas do mainstream fonográfico. Mas, quando a relação entre o rock brasileiro e o mainstream fonográfico foi desfeita, no final dos anos 80, o circuito alternativo passou a ser a única alternativa viável para os grupos que apareciam. Ao rock brasileiro, porém, não era conveniente assumir completamente as estratégias utilizadas pelos grupos que, durante as últimas décadas, circularam pelo circuito alternativo9. O principal reflexo das novas tecnologias de armazenamento e transmissão no rock brasileiro está na criação de um circuito intermediário para o rock brasileiro, em que circulam grupos com elementos do mainstream e do circuito alternativo. Após o período de sucesso, principalmente nos anos 60 e 80, os grupos de rock brasileiro foram empurrados em direção ao circuito alternativo no começo dos anos 90. E, mesmo que alguns deles tenham conseguido romper a barreira para o mainstream, muitas das características do underground foram incorporadas nas canções desses grupos. A dificuldade de interlocução com os meios de comunicação de massa, como revistas, jornais, televisão e rádios, é uma dos principais motivos desses grupos terem sido empurrados para a rede.

Assim, quando a rede e as novas tecnologias digitais abriram espaço para a distribuição de música na internet, esses grupos logo trataram de assimilar os novos recursos e ferramentas, potencializando suas atividades junto aos meios de comunicação, ao mercado fonográfico ou ao seu público. Portanto, os grupos, fanzines e selos que já lidavam de forma alternativa com seus produtos culturais, encontraram na rede o ambiente e a ferramenta ideal para a disponibilização ou veiculação de suas atividades. Mas as ferramentas oferecidas pela internet, ao aproximar a instância de produção e a de consumo, parecem atenuar a tensão, a

9 O circuito alternativo brasileiro se formou em torno de grupos que nem sempre são relacionados ao rock brasileiro e ligados a outros subgêneros do rock internacional, como o rock de garagem, o rock psicodélico, punk, heavy metal ou rock alternativo. 
disparidade, a distância entre o circuito principal e o alternativo no rock brasileiro. De forma que, hoje, não é possível distinguir claramente entre essas duas instâncias culturais e mercadológicas. Dando preferência à contraposição dos termos mainstream e underground, Rushkoff (1996), por sua vez, entende que esta dicotomia é complexificada, sobretudo, no âmbito dos meios de comunicação. Partindo de uma análise dos meios de comunicação enquanto organismos que podem ser "infectados", tanto por intenções das corporações quanto pelos atos subversivos de contestação ou pelas táticas de ações comunicativas, Rushkoff depõe a favor do caráter alternativo dos grupos marginais como uma resposta "natural" do “organismo". Assim, mainstream e underground se "contaminam" num processo de imissão recíproca.

O rock brasileiro sempre foi um fenômeno de mainstream. Desde os anos 50, os grupos de rock brasileiro são distribuídos pelas grandes gravadoras, entraram na trilhas sonoras de programas de televisão e adotam em suas canções elementos típicos do mainstream. No circuito alternativo do rock no Brasil, geralmente circulam grupos mais relacionados a subgêneros do rock internacional, como aconteceu na cena alternativa psicodélica e do rock de garagem na década de 60, na cena de rock progressivo na década de 70, no underground paulista e nas cenas de metal e punk dos anos 80. Assim, no circuito intermediário dos anos oo, circulam grupos que, ao mesmo tempo, lançam discos por gravadoras, tem videoclipes veiculados pela MTV, circulam em espaços alternativos, e disponibilizam suas canções na rede. Esse é o principal circuito do rock brasileiro nos dias de hoje, em que circulam grupos como Nação Zumbi (Futura, 2005), Bidê ou Balde (Mesmo que mude, 2005), Mundo Livre S/A (Bebadogroove, 2005), Cachorro Grande (Pista livre, 2005), Gram (Seu minuto, meu segundo, 2006), Mombojó (Homem-espuma, 2006), e, apesar de lançar discos por uma grande gravadora, até mesmo os Los Hermanos $(4,2005)$.

Em um primeiro momento, a troca de arquivos de música pela internet se resumiu à pirataria de discos lançados pelas grandes gravadoras, mas, com o passar do tempo, essa possibilidade se converteu em novas estratégias para os grupos de rock brasileiro. Essa nova possibilidade de distribuição de música pela rede, de certa forma, passou a questionar a noção de mercadoria acabada, no caso o disco ou o álbum, vendido pela indústria fonográfica tradicional. E essa situação tem um reflexo 
profundo na música popular massiva e, mais especificamente, no rock brasileiro. Um dos primeiros efeitos da tecnologia musical na indústria fonográfica foi sentido no lançamento de Kid a (Radiohead, 2000). O disco chegou às lojas em outubro, mas já era conhecido pelos fãs desde o meio do ano, quando o Kid a apareceu inteiro na internet. Era a primeira vez que um disco saía do estúdio diretamente para os ouvidos de fãs. No Brasil, a primeira manifestação dessa nova realidade acontece distribuição do terceiro disco dos Los Hermanos (Ventura, 2003). Quando o grupo ainda estava em estúdio, as gravações vazaram na internet, transformando o Ventura no primeiro álbum nacional a cair na rede antes do lançamento. Mas as conseqüências da distribuição de músicas na rede não se resumem a esses pequenos distúrbios no fluxo normal da indústria fonográfica. A partir dessas possibilidades, com o tempo, outras utilizações mais interessantes da rede foram surgindo. O grupo Mombojó, por exemplo, lançou seu primeiro disco (Nadadenovo, 2004) diretamente na internet e conseguiu uma boa visibilidade com isso. O mesmo pode ser dito de outros grupos como Cansei de Ser Sexy (CSS, 2005) e Bonde do Role (Melô do tabaco, 2006).

Mas o surgimento desse circuito intermediário não diz respeito apenas às formas de distribuição dos grupos de rock brasileiro. As práticas culturais que nascem e se desenvolvem em relação a essa reestruturação da indústria fonográfica de alguma forma reflete não apenas na circulação e consumo, mas também na própria produção. "As gravações caseiras mudaram a economia das gravações. Antes, apenas as gravadoras possuíam estúdios de gravação, porque eram os únicos que conseguiam recuperar o investimento necessário em equipamentos" (Jones, 1992:142). O desenvolvimento das tecnologias digitais para lidar com o som, em softwares que permitem a criação e modificação de ritmos e timbres no computador refletiu em uma menor definição nas fronteiras entre o rock e a música eletrônica não só na batida e nos samples, mas também na utilização de ruídos e barulhos diversos. Essa aproximação se reflete na valorização da utilização de samples e da apropriação sonora do acervo da música global ou mesmo na presença da figura do DJ em grupos como, Mombojó (Homem-espuma, 2006), Bonde do Rolê (Melô do tabaco, 2006), Montage (I trust my dealer, 2007). Esse tipo de estratégia pode ser ouvida ainda nos primeiros discos do Pato Fu (Rotomusic de liquidificapum, 1993) e, 
de alguma forma, é uma reedição da metrópole polifônica construída pelos Mutantes. Outra mudança foi a reabilitação da baixa fidelidade, low-fi, de um tipo de gravação com menos qualidade, meio aguda e ruidenta, com o uso da voz abafada nos grupos de rock - talvez pela baixa qualidade das MP3 e pela pouca potência da maioria das caixas de som de computador. Esse tipo de equalização é encontrada facilmente entre os grupos que se aproximam da cena indie, como Cachorro Grande (As próximas horas serão muito boas, 2004), Moptop (Moonrock, 2005), Vanguart (Semáforo, 2005). Para Hermano Vianna, “o CD já é passado. Talvez ninguém no futuro precise baixar nada. As músicas e filmes e textos vão estar facilmente disponíveis via sistemas de transmissão sem fio em qualquer lugar. E talvez ninguém se interesse mais por música como conhecemos hoje, e sim por jogos sonoros, onde todos participarão de remixagens eternas do que até hoje já foi produzido" (Sá, 2006: 1). Ainda não chegamos aos jogos sonoros de que falava Hermano Vianna, mas a relação entre o rock brasileiro e internet é mais profunda do que imaginamos. Muita coisa mudou e muito vai mudar.

\section{Referências bibliográficas}

DAPIEVE, Arthur. BRock: o rock brasileiro dos anos 80. São Paulo: Editora 34, 1995.

DIAS, Márcia Tosta. Os donos da voz: indústria fonográfica brasileira e mundialização dacultura. São Paulo: Boitempo Editorial, 2000.

GUTMANN, J. F. . GUTMANN, Juliana F. O contexto comunicativo como estratégia de mediação musical uma análise da situação discursiva criada pelos apresentadores do Jornal da MTV. In: Encontro Anual da Associação Nacional dos Programas de Pós-Graduação em Comunicação - Compós, Niterói. XIV Encontro Anual da COMPÓS- CDROM. Compôs/ Niterói, 2005.. In: XIV Encontro Anual da COMPÓS, 2005, Niterói. XIV Encontro Anual da COMPÓS- CDROM., 2005.

HERSCHMANN, M.; KISCHINHEVSKY,M.. Indústria da Música - uma crise anunciada. In: CONGRESSO BRASILEIRO DE CIÊNCIAS DA COMUNICAÇÃO, 28., 2005. Rio de Janeiro. Anais... São Paulo: Intercom, 2005 . 
JANOTTI JR, Jeder.Aumenta que isso aí é rock and roll: mídia, gênero musical e identidade. Rio de Janeiro:E-papers, 2003.

À Procura da Batida Perfeita: a importância do gênero musical para a análise da música popular massiva. Revista Eco-Pós. Rio de Janeiro: PósGraduação em Comunicação e Cultura da Escola de Comunicação/ UFRJ, vol.6, n.2, 2003, p. 31-46.

Heavy Metal com Dendê : música e mídia em tempos de globalização. Rio de Janeiro, E-papers, 2004.

Dos Gêneros textuais, dos Discursos e das Canções: uma proposta de análise da música popular massiva a partir da noção de gênero mediático. IN: XIVCompós, 2005, Rio de Janeiro - UFF. Anais da XIV Compós.

JONES, Steve. Rock Formation. Music, Technology, and Mass Communication. Newbury Park: Sage Publications, 1992.

JUMPEI, Márcio. Não Obrigado. Revista história do rock brasileiro: anos 80. São Paulo: Editora Abril, 2004. Rio de Janeiro:E-papers, 2003.

NEGUS, Keith. Popular music in theory: an introduction. Cambridge: Polity Press, 1999.

RUSHKOFF, Douglas. Playing the future. Nova Iorque: Harper Collins, 1996.

SÁ, Simone de. Telefones Móveis e Formas de Escuta na Contemporaneidade.Razón y Palabra, núm.41, octubre-noviembre 2004.

SÁ, Simone. Quem media a cultura do shuffle? Cibercultura, gêneros e mídias. Sessões do imaginário, v. 15, p. 1-12, 2006.

SÁ, Simone. A nova ordem musical : notas sobre a noção de "crise" da indústria fonográfica e a reconfiguração dos padrões de consumo, gepicc, 2006.

SHUKER, Roy. Vocabulário de Música Pop. São Paulo: hedra, 1999.

THORNTON, Sarah - Club Cultures. Music, Media and Subcultural Capital. Wesleyan Univ. Press. Published by University Press of New England, Hanover/ Londres. 1996.

VICENTE,Eduardo. A Música Independente no Brasil: Uma Reflexão. In: CONGRESSO BRASILEIRO DE CIÊNCIAS DA COMUNICAÇÃO, 28., 2005. Rio de Janeiro. Anais... São Paulo: Intercom, 2005. 